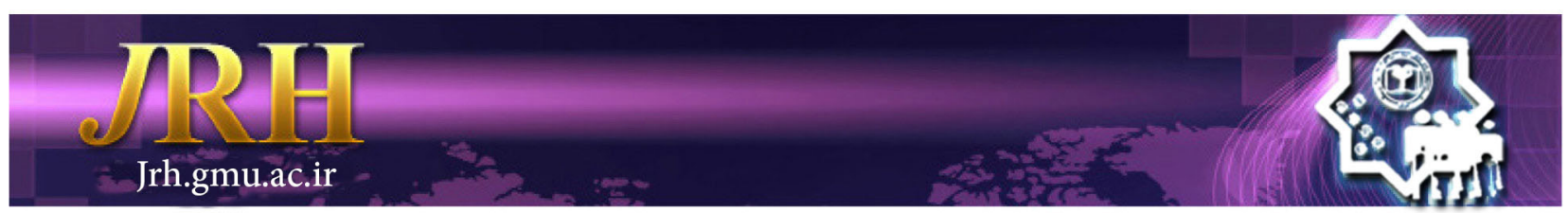

\title{
The effect of group training based on acceptance and commitment on reducing anxiety and interpersonal problems in obese women \\ Freshte Alavi Hajazi ${ }^{1}$, Atefe Nezhadmohammad Nameghi ${ }^{2}$
}

\author{
Journal of Research \& Health \\ Social Development \& Health Promotion \\ Research Center \\ Vol. 8, No.6, Nov \& Dec 2018 \\ Pages: $522-530$ \\ DOI: 10.29252/jrh.8.6.522 \\ Original Article
}

1. Department of Counseling, Faculty of Literature, Humanities and Social Sciences, Islamic Azad University, Research Branch of Tehran, Iran

2. Correspondence to: Department of Counseling, Faculty of Psychology, Islamic Azad University Branch of Karaj, Iran Email: nezhadmohamad@gmail.com

Received: 31 Oct 2017

Accepted: 15 May 2018

How to cite this article: Alavi Hajazi F, Nezhadmohammad Nameghi A. The effect of group training based on acceptance and commitment on reducing anxiety and interpersonal problems in obese women. $J$ Research \& Health2018; 8(6): 522- 530.

\begin{abstract}
Obesity is a major health problem which leads to a decline in the indicators of individuals' mental and physical health. Studies have indicated that there is a significant relationship between obesity, anxiety and depression; as well obesity can negatively affect interpersonal communication and create interpersonal problems. The present study was conducted to investigate the effect of group training based on acceptance and commitment on reducing anxiety and interpersonal problems in obese women in Tehran, Iran. This present quasi-experimental study was conducted on a statistical population comprising all obese women presenting to a health home in District 2 of Tehran. Thirty of these women were selected using convenience sampling and were randomly assigned to an experimental group $(\mathrm{n}=15)$ and a control group $(n=15)$. The participants completed the Depression Anxiety Stress Scale (DASS) and the Inventory of Interpersonal Problems (IIP32). The 15 -session treatment protocol proposed by Eifert was used for group training based on acceptance and commitment. Group training based on acceptance and commitment reduced anxiety in obese women and improved their interpersonal relationships. According to the results of the data analysis, group training based on acceptance and commitment therapy affected the psychological process of obese women and reduced anxiety and interpersonal problems of the experimental group compared to the controls in the posttest stage.
\end{abstract}

Keywords: Acceptance and commitment, Anxiety, Obesity

\section{Introduction}

The physical and psychological health of women in the community is a major factor contributing to children training and public health. A weight increase in women degrades their daily function and their effective performance in the family and society as individuals, mothers or wives, and paves the way for other physical problems, including cardiovascular diseases. Obesity is a medical condition in which fat tissue abnormally accumulates in the patient's body, which can cause the decline of health indicators such as life expectancy and quality of life. Using body mass index (BMI) is the most common method for estimating obesity [1].

Obesity increases the risk of developing different diseases, especially cardiovascular diseases, type 2 diabetes, obstructive sleep apnea, specific types of cancer, osteoarthritis and asthma. Obesity is a disease that is mainly caused by a combination of an excessive food energy input, low physical activity and genetic talent, although few cases are primarily caused 
by genes, endocrine disorders, medications and psychological disorders. As evidence to this hypothesis, some obese patients gain weight due to their slow metabolic rate despite eating little [2]. A summary of research findings suggests some psychological causes of obesity, including 1) replacing unbearable life problems with the pleasure of overeating, 2) overeating as a symptom of major diseases such as depression, 3) overeating as a kind of addiction to food, 4) responding to food signs, 5) emotional arousal and 6) stress [3]. Obesity is also a major health problem in developed and developing countries that has been growing in recent decades [4-5]. According to the results of different studies, obesity causes various psychological disorders in the patients. Obesity exerts huge negative impacts on mental health and interpersonal relationships [6-8]. Rosmond and Biortorp found relationships among unfitness, sleep disorders and the amount of antidepressants used. Obesity appears to be associated with more psychological disorders in women than in men. Obesity has also been found to be associated with personality disorders, as borderline personality disorder is more prevalent in obese individuals than in fit people. Literature also suggests significant relationships between eating disorders and borderline personality disorder [9]. Obesity can negatively affect and disrupt interpersonal relationships and cause interpersonal problems. Interpersonal relationships are a systematic, unique, progressive and selective interaction that helps people know one another and creates a common meaning among them [10]. Interpersonal relationships are a process in which information, meanings and feelings are shared with others through verbal and nonverbal messages and are based on two principles, including (1) communicators should accept the uniqueness of their behavioral characteristics and (2) they should design and send messages that represent this acceptance [11]. Interpersonal problems include interpersonal sensitivity, interpersonal ambivalence, aggression, a need for social verification and the lack of sociability. The construct of interpersonal problems refers to distrust, not being open to criticism, sensitivity to rejection, feeling violated, jealousy, avoiding sincere emotional relationships, inability of getting rid of the feeling of loss after the end of intimate relationships and inability to maintain independence and individuality in a group [12].

Obesity is significantly related to anxiety, as the most common response to stressful stimuli. Anxiety is an unpleasant emotion, some degree of which is experienced by all of us as "worry", "anxiety", "stress" and "fear" [13]. Anxiety is an undesirable mode of concern and worry that is caused by mental pressure and is associated with unfavorable complications such as heart palpitations, dyspepsia, lack of concentration and thought disorder [14]. A revised version of Diagnostic and Statistical Manual of Mental Disorders Fifth Edition (DSM-5) issued by the American Psychiatric Association defined anxiety disorders as an extreme anxiety about a number of events or activities, such as job or academic performance, on most days of the week, which cannot be controlled by the patient.

Many treatments with different approaches have been used in different groups to reduce anxiety symptoms and improve interpersonal relationships, including cognitive behavioral therapy and mindfulness-based treatments that reduced anxiety [14]. Acceptance and Commitment Therapy (ACT) is a successful therapeutic approach that improves mental health in the patients [15], and can be used for a wide range of psychological problems, situations and population types [16]. ACT is the third wave evidence-based approach to the behavior theory and uses different methods to mix acceptance and awareness strategies with commitment and behavior change strategies, and emphasizes the change in the relationship of clients with internal experiences and avoidance. The underlying principles of this therapeutic approach include 1) contacting the present time, i.e. being here and now: psychological presence and conscious relationships and involving in what occurs at any moment, 2) cognitive defusion: separation from thoughts, dreams 
and memories and letting them come and go rather than getting caught up in them, 3) acceptance: willingness to experience pain or other upsetting events without trying to curb them, 4) self as the context: one of our dimensions that is conscious about everything we think about, feel or do at any moment (pure consciousness), 5) values: desirable traits are required for continuous action. Having clear values is a basic step towards creating a meaningful life, 6) value-based action or commitment coupled with willingness to act: personal meaningful goals before eliminating unwanted experiences [17,18]. The main purpose is to create psychological flexibility, i.e. being able to decide between different alternatives of action and select the more appropriate one rather than an action being performed or actually imposed on the person only for avoiding upsetting thoughts, feelings, and memories and desires [19]. Unlike other therapeutic approaches, the ACT approach does not seek to alter the shape or abundance of distressing thoughts and emotions, but, as it has been stated, its main purpose is to enhance psychological flexibility. This approach to disorders such as chronic obesity can be based on a change in relationship with thoughts and feelings it is difficult to create better results. Research suggests the effectiveness of ACT in many disorders including anxiety, drug abuse, depression, psychological well-being, negative automatic thoughts and physical and psychological health [19-23].

Considering that research on the effect of admission and commitment education on the reduction of anxiety and interpersonal problems in women with obesity has not been made and since the number of people involved with obesity is increasing, as well as the results of various studies that Suggests the effect of an ACT approach on reducing anxiety and improving interpersonal relationships. This research aims to answer the question whether group education of concepts based on acceptance and commitment can help reduce anxiety and strengthen the interpersonal relationships of women Influenced by obesity?

\section{Method}

This quasi-experimental study was conducted using pretests and posttests. Convenience sampling was used to select 30 obese women presenting to the health home in District 2 of Tehran in spring 2016. They were randomly assigned to the experimental group $(n=15)$ and the control group $(n=15)$. Before and after eight weeks of fifteen 90-minute training sessions of the concepts, principles and techniques of ACT, the participants completed the Depression Anxiety Stress Scale (DASS) and the IIP-32. The inclusion criteria comprised an age of 20-50 years, a minimum education level of high school diploma, not simultaneously participating in other therapeutic or educational programs and a BMI of at least 30 .

Group counseling based on ACT which has been developed based on Effort and Futures. The content of the educational sessions was as follows:

The first session: Orientation and introduction of the ACT approach

The second session: Identifying private experiences and thoughts from which the members avoided

The third session: Focusing on the thoughts and feelings associated with obesity rather than the disease itself

The fourth session: Teaching creative methods of facing disappointment

The fifth session: Teaching how to control or avoid difficult psychological problems

The sixth session: Teaching fusion as well as clean and dirty discomfort

The seventh session: Teaching diffusion methods

The eighth session: Teaching conceptualized self-alignment and how to separate from it using metaphors and group exercises

The ninth session: Teaching mindfulness concepts and how to be present

The tenth session: The ninth session continues The eleventh session: Teaching and clarifying how to discriminate between goals and values The twelfth session: The eleventh session continues by doing exercises 
The thirteenth session: Focusing on values while emphasizing the dimensions of quality and health of life

The fourteenth session: Identifying and discussing barriers to value-based behaviors The fifteenth session: Evaluating, receiving feedback and terminating the sessions

DASS is a questionnaire for measuring anxiety and depression that has 21 items, This 21 -item questionnaire measures negative emotional symptoms such as depression, anxiety and stress, and comprises three subscales, including depression, anxiety and stress. Every subscale contains seven items, which are scored on a four-point Likert scale from zero (it does not apply to me at all) to 3 (it perfectly applies to me). The present study used only the anxiety subscale. Antoni et al. conducted a factor analysis on this subscale and obtained three factors, namely depression, anxiety and tension. The results of the study cited showed that $68 \%$ of the variance of the overall scale is measured by these three factors. The special value of anxiety in this study was equal to 1.23 and the alpha coefficient for the three factors was equal to 0.95 . Asgharimoghadam MA, et al reported a Cronbach's alpha of 0.92 for the dimension of anxiety. In this study, Cronbach's alpha and retest were used to examine the reliability of the instrument. Cronbach's alpha in the pretest for the anxiety domain was 0.89 . In the Pearson correlation coefficient test, the pretest and posttest were 0.625 which was significant at the level of 0.01 , in other words, the tool had an acceptable reliability [24].

The IIP is a 32 -item self-report instrument that was obtained by Barkham, Hardy and Startup as a brief version based on exploratory factor analysis of the 127-item form. The items are scored on a five-point Likert scale from zero (never) to five (strongly). In Iran, Fath et al. used factor analysis to investigate the validity of this scale and obtained six out of the eight factors obtained by Barkham et al [25]. They also confirmed the scale reliability and consistency by calculating a Cronbach's alpha of 0.82 for the entire scale.

In the present study, Cronbach's alpha coefficient in the pretest was 0.08 . The Pearson correlation coefficient between the pretest and posttest in the control group was 0.689 which was significant at the level of 0.01 that means the instrument has an acceptable reliability.

The data obtained from completing the DASS and the IIP-32 by the participants were analyzed in SPSS-20. Descriptive statistics, including percentage, frequency, mean, standard deviation, minimum and maximum, were first used in this analysis. The Kolmogorov-Smirnov test was used to investigate the normality of the data and the Levene's test to examine the homogeneity of variance within the groups. Inferential statistical tests, including multivariate ANCOVA, were ultimately used for the inference, confirmation or rejection of the study hypotheses.

\section{Results}

The descriptive and inferential findings of the present study obtained from the participants' statements indicated the effect of the concepts of ACT on treating parts of the problems of obese patients. Thirty overweight women participated in the present research. A maximum of 11 $(38 \%)$ of these women were aged 25-30 and a minimum of 2 were $45-50$. In terms of level of education, a minimum number of $2(7 \%)$ had Master of Science (MSc) and a maximum number of $12(40 \%)$ had high school diploma.

Table 1 The mean values of anxiety and interpersonal problems in the study women

\begin{tabular}{|c|c|c|c|c|c|c|c|}
\hline \multirow[b]{2}{*}{ Variable } & \multirow[b]{2}{*}{ Stage } & \multirow[b]{2}{*}{ Group } & \multirow[b]{2}{*}{ Frequency } & \multicolumn{2}{|c|}{ Pretest } & \multicolumn{2}{|c|}{ Posttest } \\
\hline & & & & Mean & $\begin{array}{c}\text { Standard } \\
\text { Deviation }\end{array}$ & Mean & $\begin{array}{c}\text { Standard } \\
\text { Deviation }\end{array}$ \\
\hline \multirow{2}{*}{ Anxiety } & \multirow{2}{*}{ Pretest } & Experimental & 15 & 21.05 & 14.85 & 16.80 & 12.68 \\
\hline & & Control & 15 & 20.40 & 12.24 & 19.53 & 8.99 \\
\hline \multirow{2}{*}{$\begin{array}{l}\text { Interpersonal } \\
\text { problems }\end{array}$} & \multirow{2}{*}{ Pretest } & Experimental & 15 & 81.33 & 17.37 & 77.46 & 18.07 \\
\hline & & Control & 15 & 80.33 & 21.81 & 81.200 & 15.70 \\
\hline
\end{tabular}


According to Table 1, the mean posttest value of anxiety decreased in the experimental group compared to the pretest stage; this reduction was, however, insignificant in the controls. Furthermore, the mean posttest value of interpersonal problems decreased in the experimental group, although the posttest increase observed in the controls was insignificant. In the following, a singlevariable ANCOVA was used to investigate the significance of this difference in the mean.

Table 2 The study variables' normality

\begin{tabular}{lccccccc}
\hline \multirow{2}{*}{ Variable } & Test & \multicolumn{3}{c}{ Kolmogorov-Smirnov test } & \multicolumn{3}{c}{ Shapiro-Wilk test } \\
\cline { 3 - 8 } & Statistic & $\begin{array}{c}\text { Degree of } \\
\text { freedom }\end{array}$ & $\begin{array}{c}\text { Significance } \\
\text { level }\end{array}$ & Statistic & $\begin{array}{c}\text { Degree of } \\
\text { freedom }\end{array}$ & $\begin{array}{c}\text { Significance } \\
\text { level }\end{array}$ \\
\hline \multirow{2}{*}{ Anxiety } & Pretest & 0.145 & 30 & 0.107 & 0.907 & 30 & 0.113 \\
& Posttest & 0.148 & 30 & 0.090 & 0.930 & 30 & 0.058 \\
\hline Interpersonal & Pretest & 0.094 & 30 & 0.200 & 0.973 & 30 & 0.629 \\
problems & Posttest & 0.076 & 30 & 0.200 & 0.990 & 30 & 0.992 \\
\hline
\end{tabular}

Study variables are normal Table 2 presents the results of the Kolmogorov-Smirnov test and the Shapiro-Wilk test for investigating the distribution normality of the data associated with every variable in the pretest and posttest. The significance level was higher than the critical value of 0.05 in both tests, suggesting that the distribution of anxiety and interpersonal problems is normal.

Table 3 The Levene's test

\begin{tabular}{lccccc}
\hline Variable & & Levene's test & $\begin{array}{c}\text { Degree of } \\
\text { freedom 1 }\end{array}$ & $\begin{array}{c}\text { Degree of } \\
\text { freedom 2 }\end{array}$ & $\begin{array}{c}\text { Significance } \\
\text { level }\end{array}$ \\
\hline \multirow{2}{*}{ Anxiety } & Pretest & 0.124 & 1 & 28 & 0.728 \\
& Posttest & 1.906 & 1 & 28 & 0.178 \\
\hline $\begin{array}{l}\text { Interpersonal } \\
\text { problems }\end{array}$ & Pretest & 1.977 & 1 & 28 & 0.171 \\
\hline
\end{tabular}

Variance within the two groups is homogene The Levene's test was used to examine the important hypothesis of homogeneity of variance of the two groups. Given that the significance levels are above the critical value of 0.05 , the test results confirmed the homogeneity of variance within the control and experimental groups for the pretest and posttest of both variables, namely anxiety and interpersonal problems.
The slope of the regression line is homogene For anxiety, the $\mathrm{F}$ value of the interaction of the independent variable and covariance equals 3.470, which is insignificant. For interpersonal problems, the $\mathrm{F}$ value of the interaction of the independent variable and covariance is 3.147 , which is insignificant. The hypothesis of the homogeneity of the regression slope is therefore satisfied for both variables.

Table 4 The ANCOVA of the effect of acceptance and commitment based training on anxiety

\begin{tabular}{lcccccc}
\hline Anxiety & $\begin{array}{c}\text { Sum of } \\
\text { squares }\end{array}$ & $\begin{array}{c}\text { Degree of } \\
\text { freedom }\end{array}$ & $\begin{array}{c}\text { Mean } \\
\text { square }\end{array}$ & F & $\begin{array}{c}\text { Significance } \\
\text { level }\end{array}$ & Eta squared \\
\hline Cumulative model & 172.568 & 2 & 86.284 & 0.724 & 0.494 & 0.051 \\
Interactive & 1602.370 & 1 & 1602.370 & 13.438 & 0.001 & 0.332 \\
Pretest & 4.033 & 1 & 4.033 & 0.034 & 0.855 & 0.050 \\
Group & 168.535 & 1 & 168.535 & 41.78 & 0.002 & 0.210 \\
Error & 3219.598 & 27 & 4.033 & & & \\
Overall & 12233.00 & 30 & & & & \\
\hline
\end{tabular}

As shown in Table 4, obese women in the experimental group were significantly different from the control in terms of anxiety by controlling the pretest $(\mathrm{p}=0.002$ and $\mathrm{F}=41.78$ ). In other words, given the mean score of anxiety in the experimental group 
compared to in the control group, ACT has reduced anxiety in the experimental group. The degree of this effect is equal to 0.210 , i.e.
$21 \%$ of individual differences in the posttest scores of anxiety in the obese patients is explained by the effect of ACT.

\begin{tabular}{lcccccc}
\multicolumn{7}{l}{ Table 5 The results of ANCOVA of the effect of ACT on interpersonal problems } \\
\hline $\begin{array}{l}\text { Interpersonal } \\
\text { problems }\end{array}$ & $\begin{array}{c}\text { Sum of } \\
\text { squares }\end{array}$ & $\begin{array}{c}\text { Degree of } \\
\text { freedom }\end{array}$ & $\begin{array}{c}\text { Mean } \\
\text { square }\end{array}$ & F & $\begin{array}{c}\text { Significance } \\
\text { level }\end{array}$ & Eta squared \\
\hline Cumulative model & 232.337 & 2 & 116.169 & 0.397 & 0.676 & 0.029 \\
Interactive & 7559.308 & 1 & 7559.308 & 25.841 & 0.001 & 0.489 \\
Pretest & 128.790 & 1 & 128.790 & 0.437 & 0.514 & 0.016 \\
Group & 643.804 & 1 & 634.804 & 2.200 & 0.042 & 0.325 \\
Error & 7898.329 & 27 & 292.531 & & & \\
Overall & 196944.00 & 30 & & & & \\
\hline
\end{tabular}

According to Table 5, the obese women in the experimental group were significantly different from those in the control group in terms of interpersonal problems by controlling the pretest $(p=0.052$ and $F=0.643)$. In other words, given the mean score of interpersonal problems in the experimental group compared to in the controls, ACT has reduced these problems in the experimental group. The degree of this effect is 0.325 , meaning that $32.5 \%$ of individual differences in the posttest scores of interpersonal problems in the obese patients is related to the effect of ACT.

\section{Discussion}

The results obtained indicated significant differences between obese women in the experimental group and those in the control group in terms of the scores of anxie and interpersonal problems. In other words, ACT has been more effective in reducing anxiety and interpersonal problems in the experimental group compared to in the controls, which is consistent with literature [27-34].

The focus of obese individuals is merely on obesity and its reduction methods. ACT in the present study taught the presenting women how to use a clear perspective to think about why their actions have not resolved their problems. These training programs have helped change the focus of the clients from obesity problems to the thoughts and feelings associated with obesity. Efforts were made during these training programs to break down the clients' verbal processes that necessitate a limited collection of responses in the face of different situations. They were also helped to act more successfully in maintaining weight loss diets and regulate their eating habits and stick to regular exercise for weight loss, which itself reduces anxiety in these people. These successes also cause positive judgements and evaluation in them. During the training sessions based on acceptance and commitment, the therapist confronted the clients with creative disappointment methods which helped them examine their previous problem-solving methods and the efficiency of these solutions in the short and long term. This method was also used by Eifert and Forsyth [27]. Using this technique helps the clients realize that their previous actions have not been effective in solving their problem (obesity) and encourages them to put aside their old instruction and take on a new method.

The treatment continued by teaching diffusion and acceptance to the clients, meaning giving up thoughts, dreams, feelings and memories. Acceptance also means providing space for painful feelings, sensations, desires and emotions [35]. By receiving this training, the subjects learnt to abandon the fight against obesity and let themselves be as they are and establish more effective relationships with others. Efforts were made in the cognitive defusion process to change the undesirable functions of thoughts and other psychological events rather than their form and content. The participants learnt to consider emotions and thoughts only as words.

ACT uses skills such as mindfulness, defusion 
and acceptance to increase psychological flexibility. The participants learnt to accept their feelings rather than to avoid or fuse them, and to understand their thoughts and thinking processes through using mindfulness and link them to objective-oriented activities. The difference between value and goal was then taught to the participants to enable them to select the goals associated with their values. In the commitment stage, the clients suffering from unfitness and obesity got to know other aspects of their life and other abilities and characteristics of themselves and made efforts to accept the status quo, obtain better self-confidence and acquire more effective communication abilities. In this stage, the clients admit their anxiety and become committed to doing what is important to them (values) despite their anxiety. Anxiety may disappear or still persist when doing these activities; however, what is certain is that they learn to live and continue their life despite their anxiety and not to allow anxiety to control and disrupt their life. Reductions in anxiety improve self-confidence and therefore develop social interactions in women. On the other hand, obese people suffer from confusion in their emotions and values as a result of negative social evaluations. Identifying inefficient feelings and emotions in social situations and improving the sense of competence have therefore been effective in improving interpersonal relationships in these people. The purpose of ACT is to help clients establish relations with their experiences in a different manner and completely get involved in a meaningful and value-based life.

Groups of men are recommended to be provided with the necessary training and compared with women in future studies. The subjects' weight loss is also recommended to be measured after the training to help determine the effect of the educational interventions on alleviating psychological problems in obese individuals.

The present study faced limitations like other studies. Limiting the samples to women and the lack of participation of men was a limitation. The limited samplesize $(n=15)$ was another limitation, which may restrict the generalizability of the results. The self-report nature of the tool and the potential awareness of the subjects about the test was also a limitation, which should be taken care of. Although the researchers were skilled, they faced problems with teaching the concepts, principles and techniques of the acceptance and commitment approach, which affected their quality of teaching. In addition, the subjects' BMI was not measured after the training programs.

\section{Conclusion}

Teachings based on acceptance and commitment appear to have taught the clients how to improve their interpersonal relationships by identifying and applying the components of the acceptance and commitment approach and using their capabilities. This has also reduced negative self-evaluations and judgments, which ultimately improved interpersonal relationships and reduced anxiety in the obese patients.

\section{Acknowledgements}

The present research was extracted from a Master's thesis written by the corresponding author in collaboration with the health home of District 2 of Tehran. The authors would like to express their sincere gratitude to all the authorities and staff of the health home of District 2 of Tehran and the supervisor, who helped conduct this study.

\section{Contribution}

Study design: AN, FA

Data collection and analysis: FA

Manuscript preparation: FA

\section{Conflicts of Interest}

"The authors declare that they have no competing interest".

\section{Funding}

The author (s) received no financial support for the research, authorship and/or publication of this article. 


\section{References}

1- Haslam DW, James WP Obesity. Lancet2005; 366(9492): 1197-209.

2- Adams JP, Murphy PG. Obesity in anaesthesia and intensive care. Br J Anaesth2000; 85(1): 91-108.

3- Parker JD, Taylor GJ, Bagby RM. The 20-item toronto alexithymia scale. III. Reliability and factorial validity in a community population. J Psychosom Res2003; 55(3): 269-75.

4- Papelbaum M, Moreira RO, Gaya CW, Preissler C, Coutinho WF. Impact of body mass index on the psychopathological profile of obese women. Rev Bras Psiquiatr2010; 32(1): 42-6.

5- Tohidi M, Kalantar Harmazi MR, Adinpour A, Dabbagh Mansheh MH, Seyyadatan J, Ranjbaramarani GH. Prevalence of overweight and obesity among adults in Shiraz in 2008. Iranian Journal of Diabetes and Metabolism2010; 9(Special letter): 43-8.

6- Dalrymple KL, Herbert JD. Acceptance and commitment therapy for generalized social anxiety disorder: a pilot study. Behav Modif2007; 31(5): 543-68.

7- Roemer L, Salters-Pedneault K, Orsillo SM. Incorporating mindfulness and acceptance-based strategies in the treatment of generalized anxiety disorder. In Baer R, ed. Mindfulness-based treatment approaches: clinician's guide to evidence base and applications. New York: Academic press; 2006. pp 52-74

8- Orsillo SM, Roemer L. The mindful way through anxiety: Break free from chronic worry and reclaim your life. New York, NY: Guilford press; 2011.

9- Forman EM, Herbert JD, Moitra E, Yeomans PD, Geller PA. A randomized controlled effectiveness trial of acceptance and commitment therapy and cognitive therapy for anxiety and depression. Behav Modif2007; 31(6): 772-99.

10- Wood J. Interpersonal communication psychology of social interaction. Translation by Firozbakhte M. Tehran: Mahtab publication; 2000.

11- Berko RM, Wolvin AD, Wolvin DR. Communication management. Translation by Eraby SM, Izadi D. Tehran: office of cultural research; 2004.

12- Razavieh A, Latifian M, Saif D. The relationship between motivational beliefs about mathematics and strategies for motivational self-regulation in gifted students. Journal of Psychology2007;11(1): 89-109.

13- Atkinson R, Atkinson RC, Smith EA, Bem DJ, Nolen-Koeksema S. Hilgard's introduction to psychology. Translation by Brahnei M, Birashk B, Beik M, et al. Tehran: Roshd publishing; 2005.

14- Ghorbani J. Educational Life Skills. Mashhad: Faraangizesh publishers; 2007.

15- Eifert GH, Forsyth J. Acceptance and commitment therapy for anxiety disorders. Translation by Faizi
A, Khaje Pour, M, Bahrami S. Tehran; Ebne Sina publishers; 1998.

16- Hayes SC, Strosahl K. A practical guide to acceptance and commitment therapy. Translation by Alizadeh Mousavi E, Pirjavid F. Mashhad; Faraangizesh publishers; 2016.

17-SegalZV, GemarM, Williams S. Differential cognitive response to a mood challenge following successful cognitive therapy or pharmacotherapy for unipolar depression. J Abnorm Psychol1999;108(1):3-10.

18- Butler G, Booth RG. Developing psychological treatments for generalized anxiety disorder. In Rapee RM, Barlow DH, eds. Chronic anxiety: Generalized anxiety disorder and mixed anxiety-depression. New York, NY, US: Guilford Press; 1991. pp. 187-209.

19- Akram Azemi Z, Ghaffari A, Sharghi A. The effectiveness of acceptance and commitment therapy based on depression, mental health and physically health in hemodialysis patients. Journal of Fundamentals of Mental Health2016; 18(Special Issue): 412-18.

20- Aarab Shaibani Kh. The effectiveness of intervention based on acceptance and commitment on emotions and thoughts control in patients with type II diabetes. Journal of Fundamentals of Mental Health2017; 19(4): 341-7.

21- Bond FW, Hayes SC, Baer RA, et al. Preliminary psychometric properties of the acceptance and action questionnaire-II: a revised measure of psychological inflexibility and experiential avoidance. Behav Ther2011; 42(4): 676-88.

22- Aslani T, Azadeh M. Effectiveness of acceptance and commitment therapy (ACT) on social well being improvement and mother-child relationship of girls in mother-headed single-parent families. Journal of Fundamentals of Mental Health2016; 18(Special Issue); 557-61.

23- Heidari S., Sajjadian I, Heidarian A. The effectiveness of Acceptance and Commitment Group Therapy on psychological distress and negative automatic thoughts in mothers of children with autism spectrum disorder. Journal of Fundamentals of Mental Health2016;18(Special Issue); 491-9.

24. Asgharimoghadam, MA, Saed, F, etal. A preliminary validation of tht depression, anxiety and stress scales (DASS) in non-clinical sample. Daneshvar (Raftar) Shahed University2008, 15(31). 23-38.

25- Fath N, Azadfallah P, Rasoolzadeh Tabatabaee K, Rahimi CH. Validity and Reliability of the Inventory of Interpersonal Problems (IIP-32). Journal of Clinical Psycology2013; 5(3): 69-80.

26- Forman EM, Herbert JD, Moitra E, Yeomans PD, Geller PA. A randomized controlled effectiveness trial of acceptance and commitment therapy and cognitive 
therapy for anxiety and depression. Behav Modif2007; 31(6): 772-99

27- Eifert GH, Forsyth JP. Acceptance and commitment therapy for anxiety disorders: a practitioner's treatment guide to using mindfulness, acceptance, and values-based behavior change strategies. Translated by Feizi A, Khjepoor M, Bahrami S. Tehran: Ebne Sina publishing: 2016.

28- Rajabi S, Yazdkhasti F. The effectiveness of acceptance and commitment group therapy on anxiety and depression in women with MS who were referred to the MS association. Journal of Clinical Psychology2014: 6(1): 29-38.

29- Izadi R, Abedi MR. Alleviation of obsessive symptoms in treatment-resistant obsessive-compulsive disorder using acceptance and commitment-based therapy. Feyz Journal of Kashan University of Medical Sciences2013; 17(3): 275-86.

30- McKay M, Lev A, Skeen M. Acceptance and commitment therapy for interpersonal problems: using mindfulness, acceptance, and schema awareness to change interpersonal behaviors. Oakland, California, US:
New Harbinger publications; 2012 .

31- Peterson BD, Eifert GH, Feingold T, Davidson S. Using acceptance and commitment therapy to treat distressed couples: A case study with two couples. Cogn Behav Pract2009; 16(4): 430-42.

32- Lee V, Robin Cohen S, Edgar L, Laizner AM, Gagnon AJ. Meaning-making intervention during breast or colorectal cancer treatment improves self-esteem, optimism, and self-efficacy. Soc Sci Med2006; 62(12): 3133-45.

33- Ossman WA, Wilson KG, Storaasli RD. McNeill JW. A preliminary investigation of the use of Acceptance and Commitment Therapy in a group treatment for social phobia. Rev Int Psicol Ter Psicol2006: 6(3): 397-416.

34- Pourfand Omran M. The effectiveness of acceptance and commitment group therapy in social phobia of students. Journal of Knowledge and Health2011; 6(2): 1-5.

35- Harris R. ACT in plain language: alphabet treatment based on acceptance and commitment. Translation by Aminzadeh A. Tehran: Arjmand publication; 2015.

\footnotetext{
Copyright (C) 2016 ASP Ins. This open-access article is published under the terms of the Creative Commons Attribution-NonCommercial 4.0 International License which permits Share (copy and redistribute the material in any medium or format) and Adapt (remix, transform, and build upon the material) under the Attribution-NonCommercial terms.
} 